ORIGINAL ARTICLE

\title{
Long term outcome of small versus appropriate size for gestational age co-twins/triplets
}

\author{
M Monset-Couchard, $O$ de Bethmann, J-P Relier
}

Arch Dis Child Fetal Neonatal Ed 2004;89:F310-F314. doi: 10.1136/adc.2002.021626

See end of article for authors' affiliations

.....................

Correspondence to: Dr Monset-Couchard, Service de Médecine Néonatale de Port-Royal Hopital Cochin, 123 Bd de Port Royal, Paris 75014,

France; secret.neonat@ cch.ap-hop-paris.fr

Accepted 19 May 2003

\begin{abstract}
Background: Small for gestational age (SGA) extremely low birthweight (ELBW $<1000 \mathrm{~g}$ ) survivors often remain small and/or have subnormal school performance. Some are twins/triplets with larger appropriate size for gestational age (AGA) co-twins/triplets.

Objective: To assess whether SGA ELBW twins/triplets remain different from their AGA co-twins/triplets. Design, setting: During 1981-1999, 353 SGA ELBW neonates were admitted to our neonatal intensive care unit: 267 survived, 54/267 were twins/triplets, and 36/54 had AGA surviving co-twins/triplets. This longitudinal study describes the growth, neurodevelopmental outcome, and school performance of these 36 sets (3-17 years). The children were classified as normal, or having minor, moderate, or severe deficiencies.

Results: Values for birth weight (mean intrapair $z$ score difference 2.26), length (2.74), and head circumference (2.62) were lower in SGA neonates than in AGA co-twins/triplets. SGA survivors remained smaller at 3-6 years of age: mean intrapair $\mathrm{z}$ score difference in weight, 1.37, height, 1.54, head circumference, 1.21. From 6 to 17 years, smaller differences persisted. Former SGA children had a tendency to have motor deficiencies (nine SGA $v$ three AGA) and mental retardation (seven $v$ four), same hearing loss (two $v$ two), but significantly more visual abnormalities $(15 \vee 11)$, behavioural disturbances (14 $v$ five), and speech problems (14 v eight). Twenty four sets were in the same normal level class, often supported by familial/professional help.

Conclusions: Although raised in the same environment, SGA ELBW survivors remained smaller and had more visual/behavioural/speech problems, but most maintained grade level parity with their AGA siblings, with appropriate help.
\end{abstract}

A recent Port-Royal study ${ }^{1}$ showed the common and, at times, very persistent failure to catch up in size of small for gestational age (SGA) extremely low birth weight (ELBW, < $1000 \mathrm{~g}$ ) survivors. Long term neurodevelopmental follow up $^{2}$ showed an increasing gap in academic performance with age, which was related in part to the socioeconomic and cultural (SEC) level of the families. Some of these SGA ELBW infants are discrepant twins/triplets with much larger co-twins/triplets. When both twins or all triplets are born alive and survive, they constitute a natural match: same gestational age, same family and therefore food and sociocultural milieu, and same age at follow up. The aim of this study was to delineate the respective roles of intrauterine growth restriction and postnatal environment in sets of discrepant twins/triplets, focusing on the catch up in size, mid and long term neurodevelopmental outcome, and school performance.

\section{MATERIALS AND METHODS}

From l January 11981 through to 31 December 1999, 783 ELBW babies born in Paris and the suburbs were admitted to the Port-Royal neonatal intensive care unit. Of these, 353 were SGA (birth weight less than the 10th centile of the weight curves produced by Lubchenco et $a l^{3}$, the standard reference at Port-Royal since 1963). Of these SGA babies, 267 survived, 54 (20\%) of which were from twin/triplet pregnancies. Seven neonates had similar ELBW SGA co-twin/ triplet(s), and 11 were "single survivors" after fetal or neonatal death of co-twin/triplet(s), leaving 36 ELBW SGA survivors with a surviving twin/triplet who was the appropriate size for gestational age (AGA; all with birth weight $>1000 \mathrm{~g}$ ). Of these 36 sets, 31 were twins and five were triplets. Eight pairs were monochorionic diamniotic twins (three ascertained twin-twin transfusion syndromes). Twenty three SGA neonates were second twins, eight were first twins, one was a first triplet, two were second triplets, and two were third triplets. Thirteen twin and one triplet pregnancies were spontaneous, six twin and one triplet pregnancies occurred after ovarian stimulation, and 12 twin and three triplet pregnancies followed in vitro fertilisation (one with intracytoplasmic sperm injection).

Median maternal age was 29 years (range 18-40). Eleven mothers presented with pre-eclampsia, one with Crohn's disease, one with $\beta$ thalassaemia, one was an HIV positive controlled substance abuser, and one had cerebral thrombophlebitis and stroke at nine weeks of gestation. Twenty one families were French, six were from Maghreb/Near East, five were from Equatorial Africa, and four were miscellaneous. The SEC level of each family was evaluated individually (parental education/work, resources, immigration status, French language fluency, type of household) and was rated as high (highly skilled, well paid, stable, two parent families), average, or low (illiterate, recent immigrant, unemployed, unstable, one parent families).

Table 1 shows anthropometric data at birth and the main clinical features and complications. The birth weight ratio ${ }^{4}$ was calculated as the SGA infant's birth weight divided by the reference ${ }^{3}$ median birth weight for the infant's gestation: the range was $0.32-0.76$ for SGA neonates and $0.68-1.15$ for AGA neonates. All neonates were checked against special weight data produced by Bertino et al for male/female twins; $\mathrm{z}$ scores were computed as well as intrapair differences in

Abbreviations: AGA, appropriate size for gestational age; ELBW, extremely low birth weight; SEC, socioeconomic and cultural; SGA, small for gestational age 
z scores. The birth weight of the smaller twin/triplet was on average $62 \%$ of that of the larger co-twin/triplet (range 38$84 \%$ ). Of 31 twin pairs, 23 were same sex ( 10 male and 13 female pairs), six SGA girls had a male AGA sibling, and two SGA boys had a female AGA sibling. In four sets of triplets, the SGA infant was matched with the same sex co-triplet, and one girl was matched with the smaller boy triplet. The 11 congenital anomalies in the SGA twins were severe in two cases (one partial trisomy 9 and one right hydronephrosis/ unexplained microcephaly), and mild in nine cases: three hypospadias (one with abnormal auditory ossicles and one with a small atrial septal defect), one unilateral choanal atresia, one bilateral choanal atresia with incomplete S3-S4 vertebrae and horseshoe kidneys, one minimal ventricular septal defect (spontaneous closure), one ovarian cyst, one isolated coccygeal foveola, and one athyreosis (immediately treated after neonatal screening). In the AGA twins, four congenital anomalies consisted of one pulmonary atresia with intact ventricular septum (successful surgery), two small atrial septal defects (one with costovertebral defects), and one minimal hypospadias with minor anomaly of auditory ossicles (similar but milder than in his SGA twin).

After discharge, 23 sets were followed at the Port-Royal Neurodevelopmental Clinic (1-15 visits) and elsewhere ("Protection Maternelle et Infantile" and/or private paediatricians, ophthalmologists, physiotherapists, psychologists, speech therapists, endocrinologists, orthopaedists, school and/or social security doctors, as needed, or required by health regulations), usually bimonthly during the first year of life, quarterly during the second year, and as clinically indicated afterwards. Thirteen sets were only seen in similar clinics in other university or high level regional hospitals, and with the same range of specialists. Anthropometric data and basic neurodevelopmental steps are stored in the child's "Carnet de Santé" (personal health record). Children seen at Port-Royal had the following: measurement of height, weight, and head circumference; standard neurophysical examinations; administration of the "Nouvelle Echelle Métrique de l'Intelligence" ${ }^{\prime \prime 6}$ (the French developmental assessment scale); assessment of vision/hearing; their parents were interviewed. Families living outside Paris or outside
France responded to detailed phone interviews with the help of the "Carnet de Santé" or to age adapted questionnaires once or twice a year (individually designed grids for anthropometric data, vision, hearing, neurodevelopmental steps and school results, and invited open comments on "problems", character, and behaviour). Additional information was obtained from paediatricians, special clinics, institutions, or special schools, including portraits, copies of school doctor evaluations and/or social security (national health service) screenings. All redundant information was cross checked for consistency.

All growth parameters were plotted against French curves (mean and standard deviations) of anthropometric measurements produced by Sempé et al, ${ }^{7}$ using the corrected age up to 3 years, then according to chronological age; $\mathrm{z}$ scores were computed. Head circumference in children above 3 years of age was plotted against Nellhaus' reference curves, ${ }^{8}$ which are similar to those of Sempé et al up to 3 years but provide references up to 18 years of age. Height and head circumference were expressed in $\mathrm{cm}$ (accuracy $0.5 \mathrm{~cm}$ ), weight in $\mathrm{kg}$ and decimals (accuracy $100 \mathrm{~g}$ in toddlers to $500 \mathrm{~g}$ in teenagers). Catch up in size was considered achieved if and when parameters reached $-2 \mathrm{SD}$ and above and remained above this limit through the most recent measurements. Growth was also assessed by changes in z scores.

Apart from size, children were considered normal if there were no motor/sensory or behavioural disturbances and no mental or school delay (absence of any deficiency). ${ }^{9}$ Minor deficiencies included mild/transient hypotonia and/or motor delay, clumsiness, subaverage fine motricity, mild sensory impairments, mild language or developmental delay, slight behavioural disturbances, or a grade level one year below normal. These deficiencies permitted normal integration but required some educational help. Moderate deficiencies included spastic diplegias, and/or moderate visual or hearing deficits, and/or mental delays with developmental quotient (DQ) between 70 and 84, grade level delays of two years or special classes, and/or disturbing behavioural symptoms (mainly hyperactivity/attention deficit). With additional intervention, integration was still possible. Major disabilities included severe cerebral palsy (hemiplegia, quadriplegia)

Table 1 Anthropometric data at birth and clinical features of the neonatal period

\begin{tabular}{|c|c|c|c|}
\hline & SGA neonates & AGA neonates & Statistical significance \\
\hline Birth weight $(\mathrm{g})^{*}$ & $849(660-990)$ & $1434(1090-2400)$ & Median difference 480 \\
\hline Mean z score & $-2.68(0.96)$ & $-0.43(0.85)$ & $2.26(1.02)$ \\
\hline Length $(\mathrm{cm})^{*}$ & $34.3(31-43)$ & $38.8(35-46)$ & Median difference 6 \\
\hline Mean z score & $-3.22(1.08)$ & $-0.50(0.93)$ & $2.74(1.40)$ \\
\hline $\mathrm{HC}(\mathrm{cm})^{*}$ & $25.4(23-27.5)$ & $28.5 .5(25-33)$ & Median difference 3 \\
\hline Mean z score & $-2.67(1.10)$ & $-0.60(0.91)$ & $2.62(1.20)$ \\
\hline One minute Apgar score $\leqslant 2 \dagger$ & $9 / 36$ & $5 / 35$ & $\mathrm{p}<0.20$ \\
\hline Hyaline membrane disease $\dagger$ & $6 / 36$ & $13 / 34$ & $p<0.02$ \\
\hline Patent ductus arteriosus $†$ & $9 / 36$ & $3 / 32$ & $p<0.10$ \\
\hline Enteropathy/NEC $†$ & $11 / 36$ & $4 / 34$ & $p<0.05$ \\
\hline Mechanical ventilation (days) $\ddagger$ & $1(0-167)$ & $3(0-20)$ & \\
\hline Bronchopulmonary dysplasia & $8 / 36$ & $2 / 35$ & $p<0.02$ \\
\hline Congenital anomalies† & $11 / 36$ & $4 / 36$ & $p<0.05$ \\
\hline Gastro-oesophageal reflux $†$ & $15 / 36$ & $7 / 35$ & $p<0.05$ \\
\hline One to four other complications $\dagger$ & $27 / 36$ & $15 / 34$ & $p<0.01$ \\
\hline Hospital stay (days)* & $77(42-257)$ & $65(15-171)$ & \\
\hline Retinopathy grade 1 or $2 \dagger$ & $6 / 31$ & $3 / 27$ & $p<0.20$ \\
\hline PIVH grade $(0-1)$ to $(I I-11) \dagger$ & $13 / 36 \S$ & $15 / 34+1$ (III-IIII) & $p<0.90$ \\
\hline Pure minor leucomalacias $\dagger$ & $5 / 36$ & $4 / 36$ & $p<0.90$ \\
\hline
\end{tabular}

For the $z$ score, the difference is the mean of the intrapair score differences. Exact $\chi^{2}$ on discordant pairs. $p$ Values in bold indicate significant difference.

"Values are mean (range).

†Values are $n / N$ where $N$ is the number of known data and $n$ is the number of cases.

$\ddagger$ Values are median (range).

§One also had minor leucomalacias.

SGA, Small for gestational age; AGA, appropriate size for gestational age; HC, head circumference; NEC, necrotising enterocolitis; PIVH, peri-intraventricular haemorrhage, bilateral grading 
and/or severe developmental delay with DQ $<70$ and/or severe sensory impairments that required intensive supervision and special education or institutionalisation, with little or no social integration.

Under the CHU Cochin policy, no approval by the institutional committee was necessary for this type of clinical research as long as the patients' anonymity was preserved.

\section{RESULTS}

The length of follow up was 3 years (corrected age) up to 17 years.

\section{Catch up in size}

All 36 sets were older than 3 years 3 months ( $>3$ years corrected age); 21 sets were above 6 years and up to 17 years of age. Age at measurements was 3 years 3 months to 5 years 4 months in 36 sets, and at the most recent measurements, 6 years 6 months to 17 years in 21 sets.

Table 2 shows that most SGA twins/triplets did not catch up in size. Even when they did catch up - that is, above -2SD - they remained shorter than their AGA siblings in $30 / 33$ sets (two pairs ended up identical in size, and one SGA girl became taller by $4 \mathrm{~cm}$ when the growth of her larger twin slowed at 8 years of age and headaches began, leading to non-contributive medical investigation). The weight of the SGA children was persistently lower in $30 / 33$ pairs (two pairs had identical weights, and one SGA girl was heavier by $1050 \mathrm{~g}$ ). Finally, SGA survivors had smaller head circumferences in 26/29 pairs (two pairs had identical head circumferences and one SGA girl had a larger head circumference by $2 \mathrm{~cm}$ ). The SGA girl who was heavier and had a larger head circumference also presented with clitoris and breast hypertrophy, but an endocrinology screening only showed a thyroid stimulating hormone concentration at the upper limit of normal and a moderately advanced bone age (she remains under close supervision and follow up). Mean intrapair z score differences remained highly significant, in spite of some attenuation above 6 years of age. Ten former SGA children had endocrinological evaluations, and two are currently receiving growth hormone treatment.

\section{Neurodevelopmental follow up and school performance}

The SEC level was high in 11 families, average in 17, and low or very low in eight.

Assessments were repeated in at least 33/36 for vision, 30/36 for hearing, and 31/36 for neurological development, and school level was known (usually along with the teacher's opinion) in 67 children (one normal boy was in Africa, four children had special education).

The two SGA children with severe congenital anomalies were excluded from the neurodevelopmental results: one girl with partial trisomy 9, deafness, and severe motor and mental retardation (living in an institution) had a probably normal AGA brother who was sent back to Africa; one boy with unexplained microcephaly, deafness, and severe retardation (special education) had a normal AGA brother.

Table 3 shows a tendency for more SGA children to have mild motor abnormalities. The severe motor deficiency in the AGA group was observed in the one girl with former grade III-III peri-intraventricular haemorrhage. Severe retardation was observed in the same girl and in an AGA boy with severe behavioural problems. Deafness was observed in a former SGA otherwise normal boy with a congenital anomaly of auditory ossicles (likely to have surgery later), while his AGA brother had a milder similar anomaly and mild hearing loss. Behavioural disturbances were much more common in SGA children, with social and academic consequences. Severe behavioural disturbances were observed very early in one pair of triplets and required special education (the three triplets are in special education and from a family of very low SEC level) as well as in a set of twins (difficulties present already in the first year of nursery school). Speech problems were also more common in SGA children (seven pairs and seven SGA children had delayed speech and/or speech therapy, one AGA child had no language with severe mental retardation).

Nine SGA and four AGA neonates with mild congenital defects were not excluded. Of nine SGA children, two were strictly normal at follow up, four had mild and three had moderate problems. All of them were at normal school level. The four AGA children had mild problems and were at normal school level.

Table 4 shows that fewer SGA children were strictly normal. All children attended school or special education. Both co-twins/triplets were at the same normal grade level in 24/34 sets: three sets were one year behind; one set was in special education; in six sets, the SGA child was one year behind while five AGA co-twins/triplets were at a normal level and one AGA co-twin was in special education. However, 15 sets were still in nursery school. In addition, at least four sets, five SGA and one AGA children received parental and/or professional help/training, although some families presented assistance with homework as "routine" procedure. Some parents struggled hard to keep the SGA child at the same grade level as the AGA co-twin/triplet.

\section{DISCUSSION}

This longitudinal study of 36 sets of discrepant ELBW SGA twins/triplets compared with their AGA co-twins/triplets showed persistent failure to catch up in size of SGA children and a higher incidence of minor/moderate deficiencies, but they usually maintained grade level parity with their cotwins/triplets.

It has been repeatedly reported that former SGA children remained smaller than their AGA counterparts, ${ }^{10-12}$ especially ELBW SGA survivors. ${ }^{13}$ The problem of restricted growth in one discrepant twin has been extensively studied by obstetricians ${ }^{14}$ interested in the cause, level of discordance, and effect on perinatal outcome. Some studies ${ }^{15}{ }^{16}$ have looked at the problem in limited series (14 pairs each) of mostly full term monozygous twins, of which a few were also SGA. One series ${ }^{15}$ showed reduced height and head circumference in the originally underweight twin at 9-17 years of age. The other $^{16}$ reported normal growth at 3-9 years of age provided that the birth weights of both twins were above the 10th centile, whereas lighter SGA twins often showed inadequate catch up growth. Even in dizygotic twins, the sex adjusted target height is the same for both children (most similar in monozygotic twins). The effect of differences in social class on catch up growth ${ }^{17}$ is not relevant in siblings. The size at birth, as defined by the birth weight ratio, ${ }^{4}$ is strongly and linearly related to body weight, height, and head circumference at 18 months of age. A recent study ${ }^{18}$ showed that fetal size is a significant predictor of postnatal growth, even taking into consideration the genetic potential in stature, as estimated by the target height. The high proportion of ELBW SGA discrepant twin/triplets who failed to catch up, and the fact that almost all of those who did catch up remained significantly shorter and lighter than their AGA co-twins/ triplets, is evidence of a lasting stunting effect of intrauterine growth restriction. Whereas it is readily accepted that an SGA girl will remain smaller than her AGA brother, differences within like-sex pairs may cause resentment in the smaller child, and SGA boys who remain smaller than their sister may be in a really difficult situation.

The neurodevelopmental outcome of former SGA children has also been analysed in series including various numbers of ELBW survivors ${ }^{24}$ 19-25 for various lengths of follow up, 
Table 2 Results of catch up growth at last follow up

\begin{tabular}{|c|c|c|c|}
\hline Catch up growth & SGA children & AGA children & Differences and/or significance \\
\hline Not achieved in weight* & $16 / 36$ & $2 / 34 \dagger$ & $p<0.001$ \\
\hline Mean z score (3-6 years) & $-1.65(1.37)$ & $06(1.56)$ & $1.61(1.08) p<10^{-9}$ \\
\hline Mean $\mathrm{z}$ score above 6 years & $-1.20(1.30)$ & $0.17(1.37)$ & $1.23 p<10^{-4}$ \\
\hline Not achieved in height* & $11 / 36$ & $3 / 34 \dagger$ & $p<0.05$ \\
\hline Mean $\mathrm{z}$ score ( $3-6$ years) & $-1.52(1.54)$ & $0.11(1.63)$ & $1.47(1.43) p<10^{-7}$ \\
\hline Mean $\mathrm{z}$ score above 6 years & $-0.86(1.60)$ & $0.32(1.64)$ & $0.94(1.13) p<0.001$ \\
\hline $\begin{array}{l}\text { Not achieved in head } \\
\text { circumference* }\end{array}$ & $4 / 34 \ddagger$ & $3 / 33$ & NS \\
\hline Mean z score (3-6 years) & $-1.56(1.14) \pm$ & $-0.08(1.61)$ & $1.27(1.74) p<10^{-9}$ \\
\hline Mean $z$ score above 6 years & $-1.00(1.29) \ddagger$ & $0.33(1.09)$ & $1.19(1.03) p<0.01$ \\
\hline Not achieved in any parameter* & $4 / 36$ & $1 / 34 \dagger$ & NS \\
\hline \multicolumn{4}{|c|}{$\begin{array}{l}\text { Differences in } z \text { score are the means of intrapair differences. Exact } \chi^{2} \text { on discordant pairs. } \\
\text { "Values are } n / N \text { where } n \text { is number in which catch up growth was not achieved, } N \text { is the number of known data in } \\
\text { children older than } 3 \text { years corrected age. } \\
\text { †One missing AGA child was a "big boy" sent back to Equatorial Africa, the other one was a big severely } \\
\text { handicapped girl (no record of weight or height). } \\
\text { fTwo children were excluded: one girl with partial trisomy } 9 \text { and one boy with severe unexplained growth failure, } \\
\text { microcephaly, and severe mental retardation. } \\
\text { SGA, Small for gestational age; AGA, appropriate size for gestational age; NS, not significantly different. }\end{array}$} \\
\hline
\end{tabular}

from 1 year ${ }^{19}$ to 18 years. ${ }^{2}$ It has been shown that motor ${ }^{4}$ and cognitive $^{423}$ abilities correlate with the birth weight ratio, being worse in lighter neonates for a given gestational age. Other studies used controls matched by gestational age, ${ }^{19-22} 24-25$ - that is, larger AGA neonates. They reported a higher incidence of minor and sometimes major ${ }^{19}$ neurological problems in SGA children, as well as poorer cognitive scores, with a significant effect of SGA even at equal neurological status, ${ }^{22}$ and more language problems. ${ }^{24}$ One study focused on discrepant twins ${ }^{26}$ and found no difference in the rate of severe handicap at 8 years of age; however, all survivors weighed more than $1000 \mathrm{~g}$ at birth. Although a number of studies have documented higher rates of cerebral palsy in surviving twins, our own low rate may be explained by the survival of both twins, as a large part of the increased rates of cerebral palsy has been related to the death of a co-twin, especially in monozygous twins and mainly with twin-twin transfusion syndrome. Therefore our higher rate of minor deficits and behavioural disturbances in ELBW SGA twins is in agreement with earlier data.

Learning difficulties in SGA full term singletons have been well documented. ${ }^{27}$ In comparison with our previous experience of ELBW SGA survivors, ${ }^{2}$ - that is, a high rate of learning difficulties that increase with age and difficulty maintaining the appropriate grade - the number of SGA/AGA pairs remaining in the same class and mostly at a normal level was a favourable finding of this study, although more SGA children eventually repeated a grade. The cognitive impairments have been in part attributed to the higher incidence of neurological abnormalities in SGA children. ${ }^{22}$ However, several studies have pointed out the role of the mother's education $^{20}$ and parental factors. ${ }^{25}{ }^{28}$ Children at high biological risk have been found to be able to catch up on their cognitive delay in a highly stimulating home environment. ${ }^{29}$ In a very large study, educational disabilities associated with adverse perinatal conditions appeared to be

Table 3 Comparative neurodevelopmental outcome

\begin{tabular}{|c|c|c|c|}
\hline & SGA & AGA & $\chi^{2}$ test \\
\hline \multicolumn{4}{|l|}{ Motor performances } \\
\hline Normal $(n / N)$ & $24 / 34^{*}$ & $31 / 35 \dagger$ & \multirow[t]{4}{*}{$\mathrm{p}<0.10$} \\
\hline Mild/transient abnormalities & 8 & & \\
\hline Moderate abnormalities & 2 & 1 & \\
\hline Severe abnormalities & 0 & 1 & \\
\hline \multicolumn{4}{|l|}{ Mental development } \\
\hline Normal $(n / N)$ & $28 / 34^{*}$ & $27 / 35 \dagger$ & \multirow[t]{4}{*}{$\mathrm{p}<0.90$} \\
\hline Mild retardation & 2 & & \\
\hline Moderate retardation & 4 & 1 & \\
\hline Severe retardation & 0 & 2 & \\
\hline \multicolumn{4}{|l|}{ Vision } \\
\hline Normal (n/N) & $22 / 34^{*}$ & $25 / 34 \ddagger$ & \multirow[t]{3}{*}{$\mathrm{p}<0.20$} \\
\hline Refraction abnormalities & 10 & & \\
\hline Strabism & 2 & 1 & \\
\hline \multicolumn{4}{|l|}{ Hearing } \\
\hline Normal (n/N) & $32 / 34^{*}$ & $32 / 34 \ddagger$ & \multirow[t]{3}{*}{$p<0.90$} \\
\hline Partial/transient hearing loss & & & \\
\hline Deafness & 1 & 0 & \\
\hline \multicolumn{4}{|l|}{ Behaviour } \\
\hline Normal (n/N) & $18 / 34^{*}$ & $29 / 34 \ddagger$ & \multirow[t]{4}{*}{$\mathrm{p}<0.01$} \\
\hline Mild disturbances & 9 & 2 & \\
\hline Moderate disturbances & 5 & $\overline{1}$ & \\
\hline Severe disturbances & 2 & 2 & \\
\hline \multicolumn{4}{|c|}{$\begin{array}{l}\text { Exact } \chi^{2} \text { on discordant pairs. The } p \text { value in bold indicates significant difference. } \\
\text { *Two SGA children with severe congenital anomalies were excluded. } \\
\text { †One missing AGA child was a "normal" boy sent back to Africa. } \\
\text { †The severely handicapped AGA child (peri-intraventricular haemorrhage grade III-III) could not be tested. } \\
\text { SGA, Small for gestational age; AGA, appropriate size for gestational age; } n \text {, number of normal children; N, } \\
\text { number of known data. }\end{array}$} \\
\hline
\end{tabular}


Table 4 Global evaluation and school level

\begin{tabular}{llll}
\hline & SGA & AGA & p Value \\
\hline Overall status & & & \\
Normal (n/N) & $8 / 34^{*}$ & $16 / 35 \dagger$ & $<0.02$ \\
Mild problems & 19 & 14 & \\
Moderate problems & 5 & 2 & \\
$\quad$ Severe problems & 2 & 3 & \\
School performance & & & \\
Normal level $(\mathrm{n} / \mathrm{N})$ & $24 / 34^{*}$ & $30 / 35 \dagger$ & $<0.05$ \\
$\quad$ One year behind & 9 & 3 & \\
Special education & 1 & 2 & \\
\hline
\end{tabular}

Exact $\chi^{2}$ on discordant pairs

${ }^{*}$ Two children with severe congenital anomalies were excluded (both with severe problems, one in an institution, one in special education). †One probably normal boy was sent back to Africa.

SGA, Small for gestational age; AGA, appropriate size for gestational age; $n$, number of normal children; $N$, number of known data.

mitigated by sociodemographic factors. ${ }^{30}$ In our general SGA study, ${ }^{2}$ we noted that cumulative minor deficiencies were often inadequately dealt with in families of low SEC level. In this study, it appears that the presence of a relatively normal large AGA twin is a stimulating factor, both as a permanent reminder of the SGA twin's deficiencies and as an incentive for the parents to achieve "equality" between co-twins/ triplets. One father (speaking of a tiny twin sister who was much smarter than her slow large brother) stated: "We tailor their activities to the needs of each child so that neither will feel at a disadvantage". This is a good policy in any family, and parents of discrepant twins appear to achieve it in most cases.

\section{Conclusions}

Although raised in the same environment, SGA ELBW twins/ triplets remain smaller than their AGA co-twins/triplets, and they have a higher incidence of minor deficiencies/behavioural problems. However, with appropriate supervision and assistance, most of them maintain grade level parity with their AGA co-twins/triplets. This highlights the important role played by schools in tackling the problems of SGA survivors, especially those from low SEC families.

\section{ACKNOWLEDGEMENTS}

We are deeply indebted to Janine Jagger-Guyenet, Professor of Neurosurgery at University of Virginia, USA, who reviewed and edited the initial manuscript (we are responsible for "linguistic atrocities" which may have been added at revision). We gratefully acknowledge the goodwill and patience of parents, teachers, paediatricians, and other specialists in repeatedly contributing data. Our heartfelt thanks also go to statisticians from the INSERM U149 (Epidemiology) for their advice.

\section{Authors' affiliations}

M Monset-Couchard, $O$ de Bethmann, J-P Relier, Service de Médecine Néonatale de Port-Royal, Hopital Cochin, Paris, France

\section{REFERENCES}

1 Monset-Couchard M, Bethmann O de. Catch-up growth in 166 small-forgestational age premature infants weighing less than $1,000 \mathrm{~g}$ at birth, all small for gestational age. Biol Neonat 2000;78:161-7.

2 Monset-Couchard M, Bethmann O de, Kastler B. Mid- and long-term outcome of 166 premature infants weighing less than $1,000 \mathrm{~g}$ at birth, all small for gestational age. Biol Neonat 2002;81:244-54.
3 Lubchenco LO, Hansman C, Dressler M, et al. Intrauterine growth as estimated from live-born birth-weight data at 24 to 42 weeks of gestation. Pediatrics 1963;32:793-800.

4 Morley R, Brooke OG, Code TJ, et al. Birthweight ratio and outcome in preterm infants. Arch Dis Child 1990;65:30-44.

5 Bertino E, Bagna R, Licata D, et al. Standard antropometrici del neonato da parto bigemino. Riv Ital Pediatr 1997;23:98-105.

6 Zazzo R, Gilly M, Verba-Rad M. La nouvelle échelle métrique de l'intelligence (2 tomes). Paris: Colin, 1966

7 Sempé M, Pédron G, Roy-Pernot MP. Auxologie, méthode et séquences. Paris: Théraplix, 1979.

8 Nellhaus G. Head circumference from birth to eighteen years. Practical composite international and interracial graphs. Pediatrics 1968;41:106-14.

9 World Health Organization. International classification of impairment, disabilities, and handicaps: a manual of classification relating to the consequences of disease. Geneva: World Health Organization, 1980.

10 Chaussain JL, Colle M, Ducret JP. Adult height in children with prepubertal short stature secondary to intrauterine growth retardation. Acta Paediatr 1994;399(suppl):72-3.

11 Hediger ML, Overpeck MD, Maurer KR, et al. Growth of infants and young children born small or large for gestational age. Arch Pediatr Adolesc Med 1998; 152:1225-31

12 Zucchini S, Cacciari E, Balsamo A, et al. Final height of short subjects of low birth weight with and without growth hormone treatment. Arch Dis Child 2001;84:340-3.

13 Peralta-Carcelen M, Jackson DAS, Goran MI, et al. Growth of adolescents who were born at extremely low birth weight without major disability. J Pediatr 2000;136:633-40

14 Warner BB, Kiely JL, Donovan EF. Multiple births and outcome. Clin Perinatol 2000;27:347-61.

15 Henrichsen L, Skinhoj K, Andersen GE. Delayed growth and reduced intelligence in 9-17 year-old intrauterine growth retarded children compared with their monozygous co-twins. Acta Paediatr Scand 1986;75:31-5.

16 Keet MP, Jaroszewicz AM, Lombard CJ. Follow-up study of physical growth of monozygous twins with discordant within-pair birth weights. Pediatrics 1986:77:336-44

17 Teranishi H, Nakagawa H, Marmot M. Social class difference in catch up growth in a national British cohort. Arch Dis Child 2001;84:218-21.

18 Karlberg J, Luo ZC. Foetal size to final height. Acta Paediatr 2000;89:632-6.

19 Pena IC, Teberg AJ, Finello KM. The premature small-for gestational-age infant during the first year of life: comparison by birth weight and gestational age. J Pediatr 1988;1 13:1066-73.

20 Robertson CMT, Etches PC, Kyle JM. Eight-year school performance and growth of preterm, small for gestational age infants: a comparative study with subjects matched for birth weight or for gestational age. J Pediatr 1990; 116:19-26.

21 Sung IK, Vohr B, Oh W. Growth and neurodevelopmental outcome of very low birth weight infants with intrauterine growth retardation: comparison with control subjects matched by birth weight and gestational age. J Pediatr 1993; 123:618-24.

22 McCarton CM, Wallace IF, Divon M et al. Cognitive and neurologic development of the premature, small for gestational age infant through age 6 : comparison by birth weight and gestational age. Pediatrics 1996;98:1167-78.

23 Hutton JL, Pharoah POD, Cooke RWI, et al. Differential effects of preterm birth and small gestational age on cognitive and motor development. Arch Dis Child Fetal Neonatal Ed 1997;76:F75-81.

24 Gutbrod T, Wolke D, Soehne B, et al. Effects of gestation and birthweight on the growth and development of very low birthweight small for gestational age infants: a matched group comparison. Arch Dis Child Fetal Neonatal Ed 2000;82:F208-14.

25 Sommerfelt K, Andersson HW, Sonnander K, et al. Cognitive development of term small for gestational age children at five years of age. Arch Dis Child 2000;83:25-30.

26 Rydhstrom H. Prognosis for twins discordant in birth weight of $1.0 \mathrm{~kg}$ or more: the impact of cesarean section J Perinat Med 1990;18:31-7.

27 Larroque B, Bertrais S, Czernichow P, et al. School differences in 20-year-olds who were born small for gestational age at term in a regional cohort study. Pediatrics 2002;108:111-15.

28 Sommerfelt K, Ellertsen B, Markestad T, et al. Parental factors in cognitive outcome of non-handicapped low birthweight infants. Arch Dis Child Fetal Neonatal Ed 1995;73:F135-42.

29 Weisglas-Kuperus N, Baerts W, Smrkovsky M, et al. Effects of biological and social factors on the cognitive development of very low birth weight children. Pediatrics 1993;92:658-65.

30 Resnick MB, Gueorguieva RV, Carter RL, et al. The impact of low birthweight, perinatal conditions, and sociodemographic factors on educational outcome in kindergarten. Pediatrics 1999. www. pediatrics.org/cgi/content/full/104/ $6 / \mathrm{e} 74$ 